\title{
Peripheral vascular disease: consequence for survival and association with risk factors in the Speedwell prospective heart disease study
}

\author{
D Bainton, P Sweetnam, I Baker, P Elwood
}

\begin{abstract}
Objective-To measure the prevalence and incidence of intermittent claudication, to describe the mortality associated with the condition, and to assess the relevance of risk factors for vascular disease. Design-A standard questionnaire on calf pain when walking was given in the prospective Speedwell study, and a range of risk factors were measured. The men were re-examined at intervals of three years, and deaths over 11 years were identified.

Setting-The general population.

Participants-All men aged 45 to 59 registered with 16 general practitioners.

Results-The prevalence of intermittent claudication increased from almost nil at ages $45-49$ to $2 \cdot 9 \%$ at ages $60-64$. The annual incidence increased from $0.3 \%$ in the youngest men to $0.5 \%$ in those in their early 60s. Intermittent claudication was related to the existence of ischaemic heart disease, particularly angina, at the first examination. The relative odds of men with angina developing intermittent claudication was 6.7 (95\% confidence interval (95\% CI) 3.6 to $12 \cdot 4)$. The risk of death in men with intermittent claudication was substantially raised. After standardisation for age and smoking the relative odds of death was $3 \cdot 8$ (95\% CI $2 \cdot 2$ to $6 \cdot 5)$. The excess was entirely from circulatory causes. Systolic blood pressure, fasting plasma glucose, triglycerides, and white cell count were all independently associated with the development of intermittent claudication, but the most striking association was with smoking.

Conclusions-Intermittent claudication is an indicator for a very high risk of death. This is only partly explained by its strong association with ischaemic heart disease.
\end{abstract}

(Br Heart F 1994;72:128-132)

Intermittent claudication is a clearly defined manifestation of peripheral vascular disease. Its prevalence is low in comparison with myocardial and cerebral manifestations of probably similar disease processes. Consequently it has been little studied and much of the epidemiological evidence comes from only a few investigations. ${ }^{1-3}$

We report here the results of a prospective study in a representative population sample of
2348 middle aged men who have been followed up for 10 years. We describe the prevalence of the symptoms, the incidence of new symptoms during the 10 year follow up, the risk factors for the condition, and its predictive power for death.

\section{Methods}

The Speedwell prospective study began in $1979 .{ }^{4}$ It was based on men who were aged between 45 and 59 inclusive on 1 September 1978 and who were registered with any of 16 general practitioners in East Bristol. A total of 2550 men were eligible for inclusion and 2348 $(92 \%)$ of these attended the Speedwell clinic for the first examination (baseline) during 1979-82. At that time the ages of the men ranged from 45 to 63 .

At the clinic the men answered the London School of Hygiene and Tropical Medicine chest pain questionnaire. This includes a set of questions on calf pain, ${ }^{56}$ and intermittent claudication is diagnosed if pain occurs in either or both calves when walking, never occurs at rest, causes the subject to stop or slow down, is relieved within 10 minutes by resting, and never disappears while walking continues. The questionnaire defines two grades of severity but because the number of affected men is small, no attempt was made to distinguish between these.

Height and weight were measured, blood pressure was recorded on a random zero muddler sphygmomanometer, and a 12 lead electrocardiogram was taken and Minnesota coded. Other data collected included details of medical history and smoking habit.

Within about a week blood was taken at another clinic, the men having fasted overnight. The blood was used for estimations of lipids, glucose, fibrinogen, plasma viscosity, white cell count, etc. Standard methods were used and these have been described in detail elsewhere. ${ }^{78}$

Ischaemic heart disease at the time of the first examination was identified from the London School of Hygiene and Tropical Medicine chest pain questionnaire and from the electrocardiogram. Any prevalent ischaemic heart disease included any or all of: angina, a history of possible myocardial infarction, or electrocardiographic evidence of ischaemia as described elsewhere. ${ }^{8}$

During the next nine to 10 years the survivors within the cohort were seen at intervals of three years and each man answered the questionnaire on symptoms again. Data on 
Table 1 Age specific prevalence of intermittent claudication at baseline and at subsequent examinations

\begin{tabular}{|c|c|c|c|c|c|c|c|c|c|c|c|c|}
\hline \multirow[b]{2}{*}{ Examination } & \multicolumn{2}{|c|}{$45-49 y r$} & \multicolumn{2}{|c|}{$50-54 y r$} & \multicolumn{2}{|c|}{$55-59 y r$} & \multicolumn{2}{|c|}{$60-64 y r$} & \multicolumn{2}{|c|}{$\geqslant 65 y r t$} & \multicolumn{2}{|l|}{ Total } \\
\hline & (n) & $\begin{array}{l}\text { With IC } \\
(n(\%))\end{array}$ & (n) & $\begin{array}{l}\text { With IC } \\
(n(\%))\end{array}$ & (n) & $\begin{array}{l}\text { With IC } \\
(n(\%))\end{array}$ & $(n)$ & $\begin{array}{l}\text { With IC } \\
(n(\%))\end{array}$ & (n) & $\begin{array}{l}\text { With IC } \\
(n(\%))\end{array}$ & (n) & $\begin{array}{l}\text { With IC } \\
(n(\%))\end{array}$ \\
\hline $\begin{array}{l}\text { Baseline } \\
3 \text { yr } \\
6 \text { yr } \\
9-10 \mathrm{yr}\end{array}$ & $\begin{array}{r}449 \\
31 \\
- \\
-\end{array}$ & $\begin{array}{l}0(0) \\
0(0) \\
- \\
-\end{array}$ & $\begin{array}{l}727 \\
598 \\
205 \\
-\end{array}$ & $\begin{array}{l}7(1 \cdot 0) \\
5(0 \cdot 8) \\
0(0) \\
-\end{array}$ & $\begin{array}{l}852 \\
686 \\
639 \\
440\end{array}$ & $\begin{array}{r}15(1.8) \\
8(1.2) \\
10(1.6) \\
6(1.4)\end{array}$ & $\begin{array}{l}318 \\
695 \\
646 \\
575\end{array}$ & $\begin{array}{r}7(2 \cdot 2) \\
24(3.5) \\
19(2 \cdot 9) \\
14(2 \cdot 4)\end{array}$ & $\begin{array}{r}- \\
45 \\
472 \\
741\end{array}$ & $\begin{array}{r}-1(2 \cdot 2) \\
18(3.8) \\
29(3.9)\end{array}$ & $\begin{array}{l}2346 \\
2055 \\
1962 \\
1756\end{array}$ & $\begin{array}{l}29(1.2) \\
38(1.8) \\
47(2 \cdot 4) \\
49(2 \cdot 8)\end{array}$ \\
\hline
\end{tabular}

*Answers were incomplete for two men seen at first examination.

In age group $65+$, the mean (maximum) age was $67.5(72)$.

IC, intermittent claudication.

incident intermittent claudication were based on the absence of calf pain at baseline and symptoms that fulfilled the diagnostic criteria on at least one subsequent three year examination.

\section{Results}

PREVALENCE OF INTERMITTENT CLAUDICATION At the baseline examination, $29(1 \cdot 2 \%)$ of the 2348 men had symptoms that fitted the strict criteria in the London School of Hygiene and Tropical Medicine questionnaire. At the reexaminations 2055, 1962, and 1756 men were seen at three, six, and nine to 10 years, and prevalence rose to $1 \cdot 8 \%, 2 \cdot 4 \%$, and $2 \cdot 8 \%$ (table 1). This rise reflects the ageing of the cohort. No cases were found in men younger than 50 , but few such men were examined. The repeated examinations suggest a prevalence of $0 \cdot 8 \%$ at ages $50-54$. Prevalence then almost doubled every five years to around $3.0 \%$ at ages $60-64$. Above age 65 , the rate of increase seemed to be less steep.

Of the 29 cases diagnosed at the baseline examination, 23 were seen at one or more of the re-examinations and 14 of them $(61 \%)$ had a positive diagnosis on at least one further occasion. For comparison, 123 cases of angina were diagnosed by the same questionnaire at baseline. Of these, 93 men were seen

Table 2 Incidence of new cases of intermittent claudication during the 10 years of follow up by age at the baseline examination

\begin{tabular}{lll}
\hline Age group & $(n)$ & With incident disease $(n(\%))$ \\
\hline $45-49$ & 422 & $13(3 \cdot 1)$ \\
$50-54$ & 658 & $22(3 \cdot 3)$ \\
$55-59$ & 749 & $36(4 \cdot 8)$ \\
$60-63$ & 265 & $13(4 \cdot 9)$ \\
Total & 2094 & $84(4 \cdot 0)$ \\
\hline
\end{tabular}

Table 3 Incidence of intermittent claudication in men with various manifestations of ischaemic heart disease (IHD) at baseline

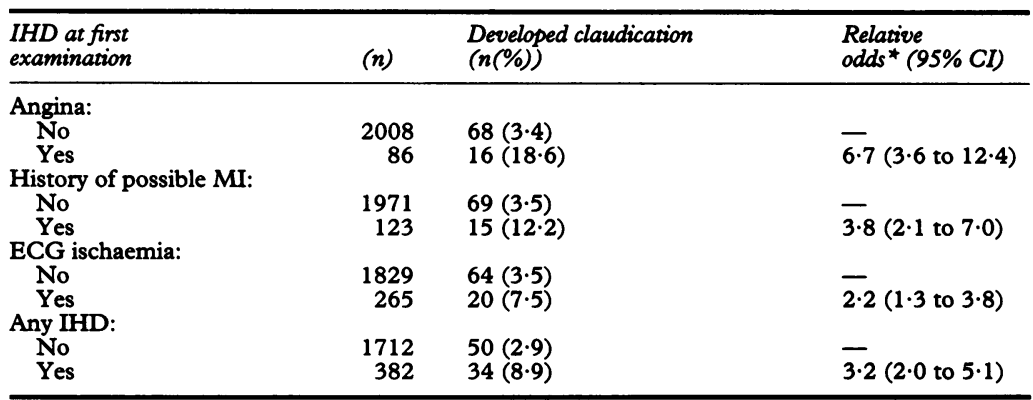

*Odds of developing intermittent claudication in men with the particular manifestation of IHD at first examination, relative to men without that type of IHD. Relative odds are standardised for first examination, relative to men without that type of IHD. Relative odds are at least once more, and $72(77 \%)$ of them had a positive diagnosis on at least one further occasion.

INCIDENCE OF INTERMITTENT CLAUDICATION Of the 2094 men who had no calf pain at baseline and who were examined at least once more, $84(4 \cdot 0 \%)$ had intermittent claudication on at least one of the further examinations. Twenty six men were first positive at the three year re-examination, 29 at the six year, and a further 29 at the nine to 10 year re-examination.

Table 2 shows age specific incidence. As might be expected, incidence increased with age, from about $0.3 \%$ a year in those initially aged 45 to 49 , to about $0.5 \%$ a year in those who were 60 to 63 at the time of the baseline examination.

\section{INTERMITTENT CLAUDICATION AND ISCHAEMIC HEART DISEASE}

Table 3 shows the incidence of intermittent claudication among men with the various manifestations of ischaemic heart disease at baseline. The odds of developing claudication were raised in men with all types of ischaemic heart disease at baseline and overall the relative odds were $3 \cdot 2$. The excess risk was particularly large for angina, with relative odds of 6.7. All these associations with incident claudication are highly significant $(p<0.001)$.

\section{MORTALITY AND INTERMITTENT}

CLAUDICATION

All men in the cohort were flagged with the NHS Central Registry when first recruited. To date, 414 have died after an average follow up of 11 years. Cause of death was unknown for three of these deaths. Because the numbers of men with intermittent claudication was small, we examined mortality in the 57 men who had the condition diagnosed at the first or the second examination. The figure shows survival curves for men with and without intermittent claudication. These are based on mortality from all causes, and show that survival was considerably reduced in men with intermittent claudication. Among such men mortality at five years was $30 \%$ and after 10 years it was $47 \%$; among men without claudication the corresponding mortalities were only $6 \%$ and $14 \%$.

Table 4 shows that of the 57 men with symptoms of claudication at or before the three year examination $29(51 \%)$ have died, compared with 385 (17\%) of the remainder. Age and smoking adjusted relative odds of 


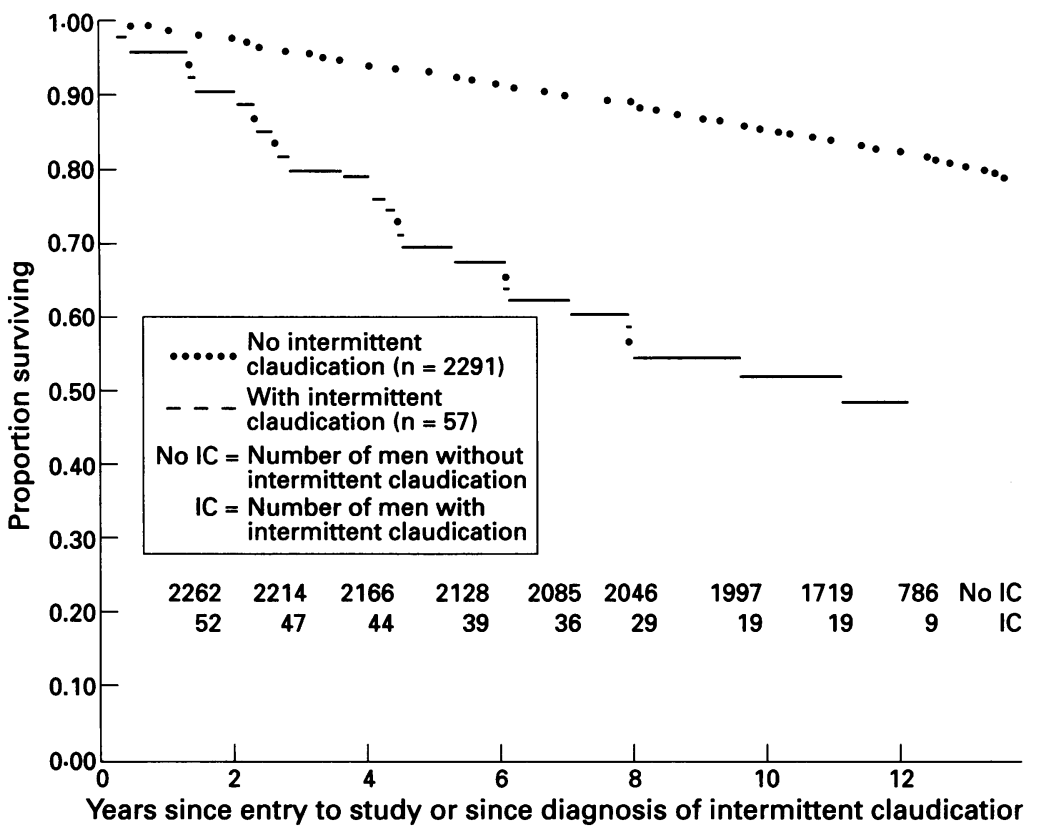

Total mortality and intermittent claudication.
INTERMITTENT CLAUDICATION AND RISK

FACTORS FOR VASCULAR DISEASE

Of the 84 incident cases, none occurred among the 330 men who had never smoked. Among the 782 ex-smokers there were 21 $(2 \cdot 7 \%)$ incident cases, and among the 980 current smokers there were $63(6.4 \%)$ new cases. This trend of increasing incidence with smoking habit was highly significant $(p<$ 0.001 ). Similarly, none of the 29 men with intermittent claudication at baseline were lifetime non-smokers.

Table 5 shows the associations between risk factors for vascular disease (other than age and smoking habit) and intermittent claudication in the 84 men who developed symptoms during the 10 year follow up. The men who developed intermittent claudication had higher systolic but not diastolic blood pressure at baseline. They also had significantly higher concentrations of total cholesterol, total triglycerides, fibrinogen, plasma viscosity, white cell count, and glucose at baseline. There was no evidence of any association with either high density lipoprotein (HDL) cholesterol or body mass index.

Many of these risk factors were interrelated. To try to determine which were independently associated with intermittent claudication, a series of multiple logistic regression models were fitted, with incidence of intermittent claudication as the dependent variable. In models that included all three lipid variables, the effect of triglycerides remained significant $(p<0.01)$, whereas the effect of total cholesterol became non-significant. In models that included all three haemostatic factors, the effect of white cell count remained highly significant $(p<0.001)$ whereas the effect of fibrinogen became nonsignificant and that of plasma viscosity disappeared. Of the other variables, systolic blood pressure $(p<0.05)$ and glucose $(p<0.05)$

Table 4 Mortality and intermittent claudication

\begin{tabular}{|c|c|c|c|c|}
\hline \multirow[b]{2}{*}{ Cause of death } & \multicolumn{2}{|c|}{ Claudication at first or at 3 yr examination } & \multicolumn{2}{|c|}{ Relative odds of death $(95 \% \mathrm{CI})$} \\
\hline & No $(n=2291)$ & Yes $(n=57)$ & $\begin{array}{l}\text { Adjusted for age, } \\
\text { smoking }\end{array}$ & $\begin{array}{l}\text { Adjusted for age, } \\
\text { smoking, prevalent IHD }\end{array}$ \\
\hline $\begin{array}{l}\text { All causes }{ }^{\star} \\
\text { All circulatory causes } \\
\text { Non-circulatory causes }\end{array}$ & $\begin{array}{l}385(16 \cdot 8 \%) \\
204 \\
178\end{array}$ & $\begin{array}{l}29(50 \cdot 9 \%) \\
21 \\
8\end{array}$ & $\begin{array}{l}3.8(2.2 \text { to } 6.5) \\
4.4(2.5 \text { to } 7.8) \\
1.5(0.7 \text { to } 3.2)\end{array}$ & $\begin{array}{l}2.7(1.5 \text { to } 4.8) \\
2.9(1.6 \text { to } 5.4) \\
1.3(0.6 \text { to } 3.0)\end{array}$ \\
\hline
\end{tabular}

${ }^{\star}$ Cause of death is unknown for three men without intermittent claudication.

Table 5 Differences in initial risk factors between men who subsequently developed intermittent claudication and those who did not

\begin{tabular}{|c|c|c|c|}
\hline Risk factor & $\begin{array}{l}\text { No intermittent } \\
\text { claudication }(n=2010) \\
(\text { mean }(S D))\end{array}$ & $\begin{array}{l}\text { Developed intermittent } \\
\text { claudication }(n=84) \\
\text { (mean }(S D))\end{array}$ & $\begin{array}{l}\text { Mean difference adjusted } \\
\text { for age and smoking } \\
(95 \% \mathrm{CI})\end{array}$ \\
\hline $\begin{array}{l}\text { Systolic BP (mm Hg) } \\
\text { Diastolic BP (mm Hg) } \\
\text { Total cholesterol }(\mathrm{mmol} / \mathrm{l}) \\
\text { HDL cholesterol }(\mathrm{mmol} / \mathrm{)} \\
\text { Total triglycerides }(\mathrm{mmol} / \mathrm{l}) \\
\text { Fibrinogen }(\mathrm{g} / \mathrm{l}) \\
\text { Viscosity }(\mathrm{cp}) \\
\text { White cell count }\left(10^{9} / \mathrm{l}\right) \\
\text { Glucose }(\mathrm{mmol} / \mathrm{l}) \\
\text { Body mass index }\left(\mathrm{kg} / \mathrm{m}^{2}\right)\end{array}$ & $\begin{array}{c}138.9(22.8) \\
86.9(13.7) \\
5.85(1.19) \\
1.11(0.37) \\
1.57(0.95) \\
3.54(0.78) \\
1.666(0.092) \\
6.94(1.88) \\
5.03(1.09) \\
25.70(3.24)\end{array}$ & $\begin{array}{c}147.5(24.3) \\
88.2(11.8) \\
6.13(1.41) \\
1.09(0.46) \\
1.92(1.07) \\
3.92(0.90) \\
1.693(0.092) \\
8.49(3.71) \\
5.38(1.65) \\
25.65(3.64)\end{array}$ & $\begin{array}{l}+7.6^{\star \star}(2.6 \text { to } 12.5) \\
+1.8(-1.2 \text { to } 4.8) \\
+0.27^{\star}(0.01 \text { to } 0.54) \\
+0.03(-0.11 \text { to } 0.06) \\
+0.33^{\star \star}(0.12 \text { to } 0.55) \\
+0.26^{\star \star}(0.09 \text { to } 0.43) \\
+0.023^{\star}(0.002 \text { to } 0.043) \\
+1.07^{\star \star \star}(0.66 \text { to } 1.47) \\
+0.38^{\star \star}(0.13 \text { to } 0.63) \\
+0.17 \text { (- } 0.54 \text { to } 0.88)\end{array}$ \\
\hline
\end{tabular}

${ }^{\star} \mathrm{p}<0.05 ;{ }^{\star \star} \mathrm{p}<0.01 ;{ }^{\star \star \star} \mathrm{p}<0.001$

BP, blood pressure; HDL, high density lipoprotein. 
remained significant as well as smoking habit, which was much the most powerful predictor.

The association with fasting glucose concentration reflected the known association between diabetes and intermittent claudication. If the 35 known patients with diabetes were excluded from the data in table 5 the difference in mean (SEM) glucose concentration between those who developed intermittent claudication and those who did not was reduced to $0 \cdot 13(0 \cdot 10) \mathrm{mmol} / 1$. Exclusion of those with diabetes made no material effect on any of the other differences shown in table 5 .

\section{Discussion}

Intermittent claudication is a progressive, disabling disease. In itself it is not life threatening, but as a manifestation of arterial disease its occurrence identifies a high risk group. In our cohort of 2348 middle aged men, nearly $50 \%$ of those with intermittent claudication at either the first or second examination were dead within 10 years of the diagnosis being made. Among men without claudication, $14 \%$ were dead within 10 years. This excess mortality was entirely attributable to deaths from circulatory causes, and was found consistently for every circulatory cause.

As with all studies of intermittent claudication we have found a strong association with each of the manifestations of ischaemic heart disease, but particularly with angina pectoris. This coexistence with ischaemic heart disease explains some of the increased mortality among men with intermittent claudication. This is confirmed in table 4 which shows that the relative odds of dying from any cause, or from any circulatory cause, fell substantially on adjustment for ischaemic heart disease at first examination. Even after this adjustment, both relative odds remain highly significant $(p<0.001)$. This implies that mortality is high among those men who have intermittent claudication but no evidence of ischaemic heart disease. Of those 24 men, seven (29\%) died during the follow up. This compared with $236(13 \%)$ of the 1833 with neither intermittent claudication nor ischaemic heart disease at first examination.

The prevalence of intermittent claudication increased sharply with age. The repeated examinations of the cohort gave estimates of prevalence of $0 \cdot 8 \%$ at ages $50-54$, rising to $2 \cdot 9 \%$ at $60-64$, and $3 \cdot 8 \%$ at $65-72$. These rates are consistent with the scientific literature; most reports gave prevalences of between $1 \%$ and $4 \%$ in men of these ages. ${ }^{2910}$

There are few estimates of incidence reported. Our results are based on small numbers but suggest that symptoms of claudication develop in around $0.3 \%$ of men a year in their late $40 \mathrm{~s}$, rising to around $0.5 \%$ of men in their early $60 \mathrm{~s}$. These estimates are similar to those given by the Basle ${ }^{11}$ and Framingham ${ }^{12}$ studies.

Smoking is undoubtedly the most important risk factor. None of the men in our series who either had symptoms when first exam- ined, or who developed symptoms during follow up, was a life time non-smoker. Furthermore, the incidence of new claudication was over twice as high among current smokers $(6.4 \%$ during the 10 years of follow up) than among the men who were ex-smokers at first examination $(2 \cdot 7 \%)$. This strong association with smoking seems to be a constant finding. ${ }^{13} 14$

Other factors that are relevant to ischaemic heart disease are also relevant to intermittent claudication. We found a positive association with systolic blood pressure, as did most ${ }^{12} 15$ but not all ${ }^{16}$ other studies. Another fairly consistent finding is a positive association with fasting glucose ${ }^{1217}$ or with diabetes mellitus. ${ }^{15}$ We also found a positive association with fasting glucose. The situation with regard to lipids is confusing. Some studies found a positive association with total cholesterol, ${ }^{12} 16$ others found a negative association with HDL cholesterol but no association with total cholesterol or triglyceride, ${ }^{18}$ whereas others found a positive association with triglycerides and no association with HDL or low density lipoprotein cholesterol. ${ }^{17}$ Fowkes et al reported positive univariate associations with both non-HDL cholesterol and total triglycerides. ${ }^{15}$ On multivariate analysis the association with non-HDL cholesterol remained highly significant whereas that with triglycerides largely disappeared. Our univariate results are similar, but on multivariate analysis we found the opposite effect. Total triglyceride remained strongly associated with the incidence of intermittent claudication, whereas the effect of total cholesterol was small, and not significant. It seems likely that these differences between studies arise because of the few cases in each study due to the rarity of the condition.

Interest is developing in the relevance of thrombosis related factors to ischaemic heart disease. Most of the evidence in the scientific literature linking haemostatic factors with peripheral vascular disease is cross sectional although the Framingham study has shown fibrinogen to be predictive. ${ }^{19}$ Raised fibrinogen concentrations have also been shown to be associated with the progression of the disease. ${ }^{20}$ Our data on incident disease show univariate associations with fibrinogen, plasma viscosity, and white cell count (table 3 ) that are independent of smoking habit. Lowe et al showed cross sectional associations between peripheral arterial disease and both whole blood and plasma viscosity. ${ }^{21}$ They concluded, after multivariate analysis, that both viscosity and fibrinogen made independent contributions to peripheral arterial disease. We found that the effect of viscosity disappeared on multivariate analysis, and that the association between incident intermittent claudication and fibrinogen became non-significant. The association with white cell count, however, remained highly significant $(p<0.001)$. We have previously suggested that white cell count is an independent predictor for ischaemic heart disease.$^{8}$ Because of this further association with the development 
of intermittent claudication, white cell count surely merits some further attention.

In summary, the most important aspect of intermittent claudication for clinical practice is the fact that it is a marker for a high risk of death from all circulatory causes. This arises only partly because of its coexistence with ischaemic heart disease. Mortality is also high in patients with intermittent claudication with no evidence of ischaemic heart disease.

1 Kannel WB, Skinner J Jr, Schwartz MJ, Shurtleff D. Intermittent claudication: incidence in the Framingham Study. Circulation 1970;41:875-83.

2 Davey Smith G, Shipley M, Rose G. Intermittent claudication, heart disease risk factors and mortality: the Whitehall Study. Circulation 1990;82:1925-31.

3 Criqui MH, Langer RD, Fronek A, Feigelson HS, Klauber MR, McCann TJ, Browner D. Mortality over a period of 10 years in patients with peripheral arterial disease. $N$ 10 years in patients with perit
Engl $\mathcal{F}$ Med 1992;326:381-6.

4 Caerphilly and Speedwell Collaborative Group. Caerphilly and Speedwell collaborative heart disease studies. $f$ and Speedwell collaborative heart disease

5 Rose GA. The diagnosis of ischaemic heart pain and intermittent claudication in field surveys. Bull World Health mittent claudication in

6 Rose G, McCartney P, Reid DD. Self-administration of a questionnaire on chest pain and intermittent claudication. British fournal of Preventative and Social Medicine

7 Bainton D, Miller NE, Bolton CH, Yarnell JWG, Sweetnam PM, Baker IA, et al. Plasma triglyceride and high density lipoprotein cholesterol as predictors of ischaemic heart disease in British men. The Caerphilly and Speedwell collaborative heart disease studies. $\mathrm{Br}$ Heart $\mathcal{f} 1992 ; 68: 60-6$

8 Yarnell JWG, Baker IA, Sweetnam PM, Bainton D, O'Brien JR, Whitehead PJ, Elwood PC. Fibrinogen, viscosity, and white blood cell count are major risk factors for ischemic heart disease. The Caerphilly and
Speedwell collaborative heart disease studies. Circulation $1991 ; 83: 836-44$

9 Hughson WG, Mann JI, Garrod A. Intermittent claudication: prevalence and risk factors. $\mathrm{Br} \mathrm{Med} \mathcal{f} 1978$; tion: preval $1379-81$.

10 Fowkes FGR, Housley E, Cawood EHH, Macintyre CCA Ruckley CV, Prescott RJ. Edinburgh artery study: prevalence of asymptomatic and symptomatic peripheral arterial disease in the general population. Int $\mathcal{F}$ Epidemiol rial disease in the

11 Da Silva A, Widmer LK. Occlusive peripheral artery disease. The Basle study. Bern: Huber, 1980.

12 Kannel WB, McGee DL. Update on some epidemiological features of intermittent claudication: the Framingham study. F Am Geriatr Soc 1985;33:13-8.

13 Lord JW. Cigarette smoking and peripheral atherosclerotic occlusive disease. FAMA 1965;191:249-51.

14 Kannel WB, Shurtleff D. The Framingham Study Cigarettes and the development of intermittent claudication. Geriatrics 1973;28:61-8.

15 Fowkes FGR, Housley E, Riemersma RA, Macintyre CCA, Cawood EHH, Prescott RJ, Ruckley CV. Smoking, lipids, glucose intolerance, and blood pressure as risk factors for peripheral atherosclerosis compared with ischemic heart disease in the Edinburgh artery study. Am ₹ Epidemiol 1992;135:331-40.

16 Davey Smith G, Shipley MJ, Marmot MG. Prognosis of intermittent claudication. In: Fowkes FGR Epidemiology of peripheral vascular disease. London: Springer-Verlag, 1991:315-24.

17 Criqui MH, Langer RD, Fronek A, Feigelson HS, Klauber MR. Large vessel and isolated small vessel disease. In: Mowkes FGR, ed. Epidemiology of peripheral vascular disFowkes FGR, ed. Epidemiology of peripheral
ease. London: Springer-Verlag, 1991:85-96.

18 Shaper AG, Wannamethee SG, Walker MK. Risk factors and cardiovascular outcome. In: Fowkes FGR, ed. and cardiovascular outcome. In: Fowkes FGR, ed. Epidemiology of peripheral vasc

19 Kannel WB, D'Agostino RB. Update of fibrinogen as major cardiovascular risk factor: the Framingham study. $\mathcal{F}$ Am Coll Cardiol 1990;15:156A.

20 Dormandy JA, Hoare E, Khattab AH, Arrowsmith DE Dormandy TL. Prognostic significance of haematological and biochemical findings in patients with intermittent claudication. BMF 1973;576-81.

21 Lowe GDO, Donnan PT, McColl P, Lennie SE, Riemersma RA, Dawes J, et al. Blood viscosity, fibrinogen and activation of coagulation and leucocytes in peripheral arterial disease: the Edinburgh artery study. Br $\mathcal{f}$ Haematol 1991;77(suppl 1):27. 